\title{
INTELLIGENCE AND TOLERANCE / INTOLERANCE FOR UNCERTAINTY AS PREDICTORS OF CREATIVITY
}

\author{
Tatiana V. Kornilova, \\ Sergey A. Kornilov \\ Lomonosov Moscow State University \\ Moscow
}

\begin{abstract}
The present paper describes two studies that investigated incremental predictive value of tolerance and intolerance for uncertainty in predicting creativity. The first study shows significant positive incremental predictive power of tolerance for uncertainty over general intelligence in predicting creativity. The second study reveals a negative relationship between intolerance for uncertainty and creativity with fluid intelligence scores being already accounted for. Overall, tolerance for uncertainty promotes creativity, whereas intolerance for uncertainty impedes it, demonstrating that creativity draws on both intellectual potential and processes of uncertainty acceptance.
\end{abstract}

Keywords: uncertainty, ambiguity, tolerance for uncertainty, intelligence, creativity

Tolerance is viewed as one of the major principles leading the humanization of psychology as a field (Ball, 2009). In his recent methodological paper, Zinchenko (2007) discusses whether the topic of an individual dealing with an uncertain environment is new for psychology. Coping with and overcoming uncertainty is viewed as one of the central constructs for psychology of judgement and decision making (Kornilova, 2003). Russian studies that used translated / adapted versions of some tolerance for ambiguity / uncertainty measures have mostly focused on broadening the field of behavior and choice regulation by explicitly including and operationalizing the domain of personality (Kornilova, 2009; Soldatova \& Shaigerova, 2008). We argue that studies of tolerance

This research and the publication of this chapter were supported by a grant № 10-06-00416a from the Russian Foundation for Humanities (RGNF). Correspondence regarding this paper should be addressed to Sergey A. Kornilov. E-mail: sa.kornilov@gmail.com 
Intelligence and Tolerance / Intolerance for Uncertainty as Predictors of Creativity 241

for uncertainty should also be focused on illuminating the role of this personality trait in thinking strategies and creative cognition.

The popularization of the psychology of abilities (including intelligence and creativity) at the close of the XX century spurred an increasing interest in the field. Hunt (1997) broadly described the general pattern of growth in the number of studies in social and behavioral sciences and medicine as "explosive growth." Psychology of creativity, however, seems to be still at the "pre-explosive" stage, given the unique complexity of the phenomenon. One of the possible qualitatively new directions in this domain is to employ an exhaustive search for integrative constructs of regulation of creativity. In this case, the problem of the relationship between cognitive processes and creativity might be addressed by studying constructs that mediate this relationship, such as the processes of accepting and overcoming uncertainty. Creative tasks are usually characterized by uncertainty and draw on strategies for overcoming it but do not specify the means and processes by which this can be accomplished. Thus, the degree to which creativity is a product of realization of one's intellectual potential versus the person's readiness to act and make choices in new and uncertain environment is established in the real time of the actual genesis of new formations. We suggest that the latter is best apprehended by the concept of tolerance for uncertainty.

Creativity is most often defined as the ability to generate products (ideas, objects, etc.) that are original, subjectively and objectively novel, elaborate and task appropriate (e.g., Hunsaker \& Callahan, 1995; Runco, 2004). Rhodes (1961/1987) suggests the following structural categorization of creativity:

1) creative person,

2) cognitive processes recruited for creation,

3) environment, in which creation takes place,

4) creative product.

Such multidimensionality, along with the problems distinguishing between the predictors of creativity, the potential (and ability) to create, creative processes and creative products, impede progress in the field (for example, in comparison with the fields of clinical and educational psychology). One of the most recent advances in the field was the publication of Ma's (2009) meta-analysis of variables associated with creativity, in which creativity was redefined as "the ability to reorganize the 
available knowledge, information, cues, facts and / or skills in a person's reservoir to generate new ideas or useful solutions" (p. 39).

The classic studies that employed similar definitions were conducted within the psychometric approach to creativity (Plucker \& Renzulli, 1999). This approach almost entirely equated creativity with divergent thinking (Guilford, 1962) and emphasized the development of creativity measures operationalized as measures of the ability to be fluent, flexible, generate new and original ideas, produce remote association etc (e.g., Torrance, 1972; Mednick, 1962; see also Kerr \& Gagliardi, 2003 for a review).

One of the most developed frameworks within this approach seeks to reveal the sources of individual differences in creativity. Among these, according to the Rhodes's classification mentioned above, the relationship between creativity, intelligence and personality received the most attention. Studies of the relationship between creativity and intelligence showed that the correlation between them is usually around $r=$ .30 (Batey \& Furnham, 2006; Kornilov \& Grigorenko, 2010; Ma, 2009), and also that this relationship (according to the threshold theories see Guilford, 1981; Torrance, 1962) is not fully linear with a somewhat low variation in creativity when intelligence is low, and a high variation when the latter is high. The overall pattern suggested a relatively low percent of variance in creativity measures explained by general cognitive ability. This relationship is attributed to creativity drawing on information processing capacity, knowledge acquisition and general adaptation (Batey \& Furnham, 2006; Gottfredson, 1998; Mednick, 1962; Weisberg, 1999; and others).

It is clear, however, that creativity (both as a process and as a product) cannot be simply reduced to general cognitive functioning and cognitive "reservoir" of a person. Among approaches that go beyond classical psychometric framework, there are also mystical, motivational, socio-personality, existential (and humanistic), pragmatic and dynamic approaches (e.g., May, 1976; see Plucker \& Renzulli, 1999, for an overview). For example, studies within these approaches clarified the relationship between motivational and attentional characteristics in the state of "flow" involved in generating creative products (Nakamura \& Csikszentmihalyi, 2003), and also revealed relationships between the processes of motivational and cognitive regulation of creativity (Collins \& Amabile, 1999). Case studies of eminent creators that possess certain personality traits 
Intelligence and Tolerance / Intolerance for Uncertainty as Predictors of Creativity 243

and similarities observed between typical descriptions of highly creative individuals and individuals with mental disorders motivated such research avenues as studying the neurobiological foundations of creative cognition (see Kaufman et al., 2010 for an overview) and the relationship between personality and creativity (Batey \& Furnham, 2006).

However, most of these studies selectively restricted their scope to relationships between creativity and Big Five model with corresponding personality traits. They showed that personality traits most closely related to creativity are Openness and Extraversion (e.g., Furnham \& Bachtiar, 2008; Wolfradt \& Pretz, 2001; see also Ma, 2009). As Batey and Furnham (2006) point out, the difficulties in this domain are related to the lack of clear definitions and problems of creativity measurement along with the mentioned selectivity of the studies and theoretical accounts that motivated them. We maintain that the most promising way to address these issues is to adopt the approaches that aim at revealing integrative contexts and constructs and take into account the interactions between different basic processes that mediate creative activity.

Taking as its basis Vygotsky's (1934/1962) notion of the unity of intellect and affect, developed within his cultural-historical framework, Russian psychologist Tikhomirov (Babaeva et al., 2008) has developed the so-called Sense Theory of Thinking. The theory views new formations as distinct psychological components - among them, individual representations of meanings and goals. Personal and operational senses are what an individual has acquired during problem solving. These "acquisitions" do not exist before the solution is found and broadly characterize the level of creativity exerted by a person. According to this criterion of creativity, we view these new formations as reflecting the actualization and realization of a person's personality and intellectual potential, and being related to the interaction of these processes in the self-regulation of decisions. This idea of multiplicity and multidimensionality of the processes of regulation in decision making was later developed in studies of intellectual decision making (Kornilova \& Tikhomirov, 1990).

A similar approach is presented by the so-called confluence approaches to creativity: the Investment Theory of Creativity (Sternberg \& Lubart, 1996), the Amusement Park Theory of Creativity (Baer \& Kaufman, 2005) and Averill's (2005) emotional creativity approach, to name a few. Averill (2005) argues for replacing the trichotomy of intelligence, 
creativity and emotion with the triunity. He argues against novelty as a pure measure of creativity, pointing to the fact that intellectual potential also includes the ability to find new solutions to complex problems.

It is worth reminding the reader of the scarcity of even relatively clear answers to the questions related to specific processes of cognitive or personality regulation crucial to the issue of which processes (of cognitive and personality regulation) are dominant in the defining the new formations. For example, the question of the role of intellectual potential in creativity remains unanswered. In addition, theoretic accounts for specific personality traits affecting the process of creating something new (ideas, objects, solutions, etc.) are also sparse.

The concept of new formations suggests that a person overcomes the insufficiency of cues and goes beyond the task and situation requirements - thus, demonstrating the readiness to overcome uncertainty. Starting with the seminal papers of Frenkel-Brunswick (1948; 1949), the concept of tolerance for ambiguity / uncertainty has been dichotomously placed in either personality traits or cognitive strategies. Recent studies of tolerance for uncertainty show that separate and distinct processes are related to accepting uncertainty versus a willingness to achieve clarity, and get a full set of cues (Kornilova, 2009).

We have been referring to both tolerance for ambiguity and tolerance for uncertainty concepts. The presence of these seemingly fully overlapping terms made it difficult to clarify both of them. In psychological literature published primarily in English, two terms existed: tolerance for ambiguity as tolerance for a lack of clarity, double or multiple meanings of the stimuli and complexity of their interpretation, and tolerance for uncertainty as tolerance for a lack of confidence and certainty in the context of insufficient information. Intolerance for uncertainty was viewed as either an independent construct or just another point on the continuum of tolerance for uncertainty. German literature, on the other hand, most frequently used the term uncertainty (Unsicherheit), which refers to subjective uncertainty and lack of confidence (Kahneman, Slovic, \& Tversky, 1982). Such uncertainty acts as one of the components of the regulation of decision making by determining the strategies of information search and acquisition in the uncertain environment. The former might, for example, be revealed by the number of questions a person asks (Dorner, 1997) or the number of properties required for decision making (Ladouceur, Talbot, \& Dugas, 1997). The higher the uncertainty, 
Intelligence and Tolerance / Intolerance for Uncertainty as Predictors of Creativity 245

the higher is the probability of examining an alternative hypothesis previously ignored or devalued (McKenzie, 1998).

In Russian psychology, subjective uncertainty was studied within the context of the regulation of cognitive strategies by Gurova (1976) and Tikhomirov (1969). The latter showed that "the process of problem solving consists of reducing the initial uncertainty, in the active selection of information, which is the result of a person's own actions" (p. 73). Studies within this framework revealed the unity of mediation that occurs in activity and dynamic characteristics of reducing uncertainty. They were the first to suggest that overcoming uncertainty is related to the intensity of new formations (a criterion for creativity, as mentioned above) in decision making (Kornilova \& Tikhomirov, 1990). One of the first English research papers examining the relationship between creativity and tolerance for uncertainty has only recently been published by Zenasni, Besancon and Lubart (2008), although this relationship was suggested by Vernon in 1970: he argued that tolerance for uncertainty leads to dissatisfaction with partial or nonoptimal solutions.

As we have argued, there exists an established dichotomy between the studies of tolerance for uncertainty in information processing (Kahneman, Slovic, \& Tversky, 1982) versus studies of a tolerant personality (Soldatova \& Shaigerova, 2008). We suggest moving towards viewing accepting or rejecting uncertainty within the integrative context of the regulation of thinking strategies and decision, which, according to the new formations criterion, can be viewed as involving creativity. Such rejection / acceptance is involved in all situations that require new formations, thus, one of the possible research questions may be formulated as following: which processes mediate the generation of a creative product? The answer to this question would require revealing and clarifying the unique contribution of both intellectual potential and personality traits of tolerance / intolerance for uncertainty to creativity.

Sternberg (2006) explicitly includes tolerance for uncertainty / ambiguity in his theories of both creativity and wisdom developed within WICS framework as one of the requirements for the realization of the creative potential. Humanistic psychologists also explicitly describe the act of accepting the challenge of uncertainty, which occurs when a potential creator's capacities finally meet the situation and its requirements (May, 1976). Unfortunately, there has been few published studies of the relationship between creativity and uncertainty. Wolfradt and 
Pretz (2001) investigated the interrelations among personality traits and creativity and revealed the empirical factor that included openness to experience, extraversion, tolerance for interpersonal ambiguity and creativity, partially replicating the results of Tegano's (1990) study. The significant positive correlation between tolerance for ambiguity and creativity was also revealed in a study by Zenasni, Besancon and Lubart (2009).

Kitaev-Smyk (2007) suggested the relationship between personality and situational regulation of creativity by positing a link between creative insights and stress dynamics. Here uncertainty leads to confusion, losing of the goal-directedness, loneliness and confrontational "background," which are viewed as the prerequisites for the future creative tension. Thus, experiencing uncertainty is closely tied to creative process.

Overall, the views of creativity as the ability distinct from intelligence or as one of the personality traits are in opposition to the approaches that suggest studying creativity as components, stages or one of the processes of the actualization of creative thinking. The general hypothesis that motivated the two studies presented in this paper was that creative thinking that mediated the generation of a creative product requires the person's readiness to positively resolve uncertainty (reduce it through new formations). Thus, individual differences in creativity should be related to personality traits involved in uncertainty acceptance (tolerance / intolerance for uncertainty, readiness to rely on intuition and risk readiness). Intelligence is viewed as another component that interacts with uncertainty acceptance in creativity.

The present two studies tested the following hypothesis:

H1. Creativity is positively related to tolerance for uncertainty and negatively related to intolerance for uncertainty.

$\mathrm{H} 2$. Creativity is positively related to general intelligence.

H3. Intelligence, tolerance and intolerance for uncertainty have unique predictive validity in creativity.

\section{Methods}

\section{Participants}

This paper analyzes the data obtained in two large-scale studies of abilities and personality. Both studies provided data on general ability, creativity and tolerance / intolerance for uncertainty for student samples. 
Intelligence and Tolerance / Intolerance for Uncertainty as Predictors of Creativity 247

The first study (Kornilova, 2009) adapted and validated the New Questionnaire of Tolerance for Uncertainty (NQTU) and examined the relationship between different personality traits in decision making. 623 students participated in the study (age ranged from 17 to $48, M=21.07$, $S D=4.71 ; 421$ were male, 202 were female). For 204 of these 623 , we also obtained data on creativity using the Cartoon Task (see below) and 178 were also administered the IST-70 (see below) with the overlap between IST-70 and Cartoon Task being $\mathrm{n}=121$.

The second study (Kornilov, Grigorenko, \& Smirnov, 2009; Kornilov \& Grigorenko, 2010) validated the complex assessment of analytical, creative and practical abilities and examined the relationship between these abilities and academic achievement in students. 441 students participated in the study (age ranged from 17 to $60^{1}, M=21.06, S D=5.08 ; 86$ were male, 355 were female). All of the participants were administered the Creative Stories subtest and two of the CFIT Scale 2 subtests providing data on creativity and fluid intelligence, respectively. Of these, 174 were also administered the TN-23 questionnaire (see below) that measures riskiness and intolerance for uncertainty.

\section{Measures}

Tolerance / intolerance for uncertainty

1. The previously validated New Questionnaire of Tolerance for Uncertainty (NQTU, or NTN in Russian) was used to measure variables associated with acceptance of uncertainty. This questionnaire proved to be superior to other existing measures in both psychometric properties and the scope of the traits measured (Kornilova, 2009): figure 1 shows the SEM-model fitted in Kornilova's (2009) study. The questionnaire includes three scales:

Tolerance for Uncertainty (TU) as readiness to make decisions and act in uncertain situations, openness to new ideas, changing stimuli and changing thinking strategies. In the SEM model, this variable was one of the indicators of the latent variable of acceptance of uncertainty and risk (which also included intuitive ability). Here, tolerance for uncertainty is a construct relatively independent of intolerance for uncertainty.

\footnotetext{
1 The present age range was due to the inclusion of the participants pursuing the second degree (adults returned to school).
} 


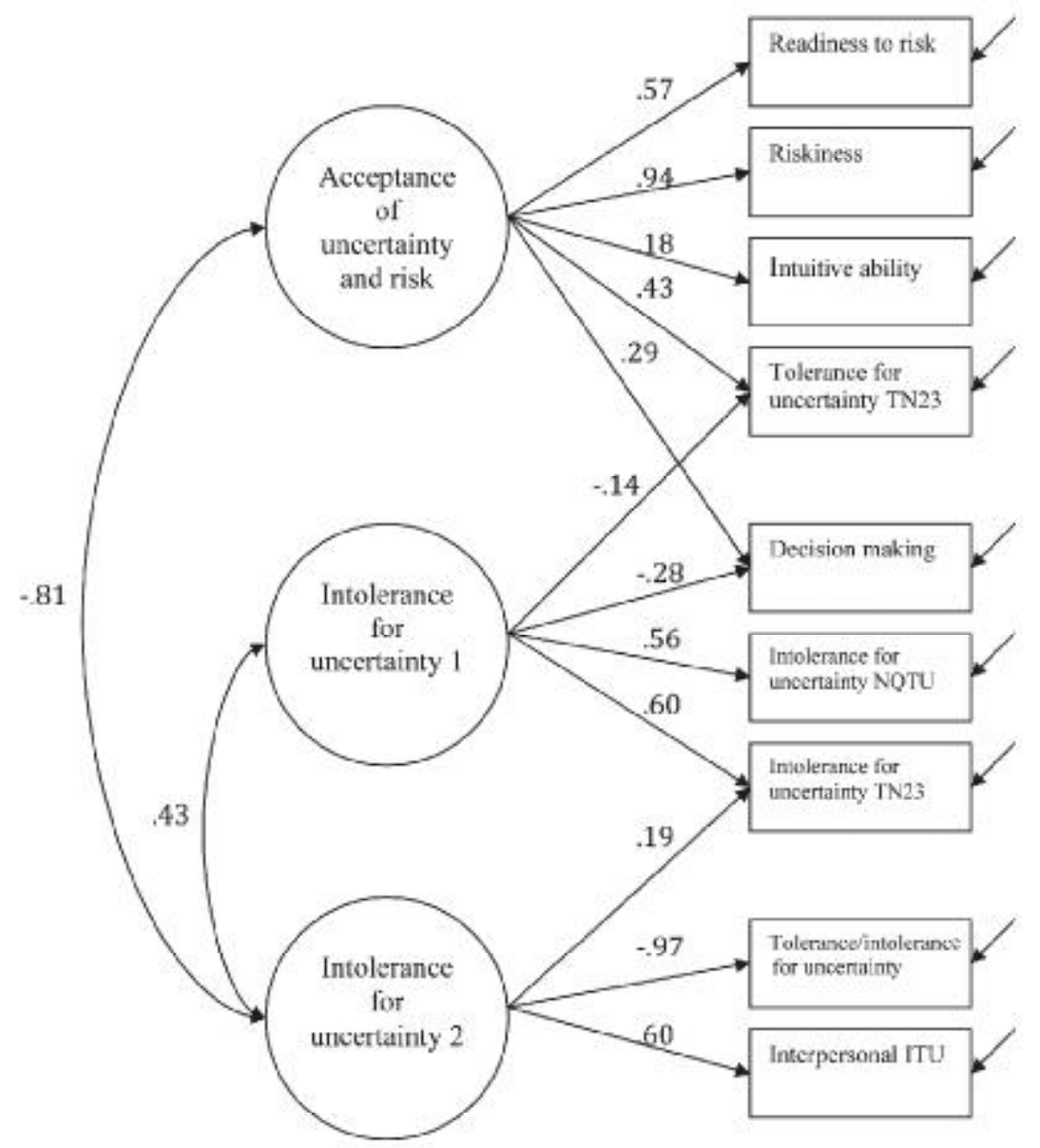

Figure 1. The SEM model fitted by Kornilova (2009)

Note: $\mathrm{CFI}=.96, \mathrm{RMSEA}=.041(95 \%$ CI $.022, .060) \cdot \chi^{2}(22)=42.83$.

Intolerance for Uncertainty (ITU) as willingness to achieve clarity in the world (including the world of ideas), rejection of uncertainty in judgements, rigidity and rationality (as directed towards acquiring maximum information required for making a decision). 
Intelligence and Tolerance / Intolerance for Uncertainty as Predictors of Creativity 249

Interpersonal Intolerance for Uncertainty (IPITU) as a more specific (and uni-dimensional) personality trait with a bipolar scale of acceptance / rejection of uncertainty in interpersonal relationships. IPITU measures the degree to which a person is intolerant to vagueness in things left unsaid and uncertainty in communication with others and the degree to which a person seeks to clarify positions, attitudes and behavioral strategies.

2. TN-23 is a Russian adaptation of La Rosa's questionnaire developed by Shalaev (2007). The questionnaire includes three scales: intolerance for uncertainty (IU), safety, and riskiness (RISK). The latter measures the acceptance of uncertainty and willingness to experiment to acquire experience in new or unpredictable situations. Intolerance for uncertainty measures the inability to go beyond established concepts, beliefs, attitudes, hypotheses and judgments.

\section{Cognitive abilities}

1. The IST-70 (Amthauer, 1973) is a measure of general cognitive ability, it consists of 9 subtests, 8 of which (except memory) were used in the study. The test provides measures of General IQ and Verbal, Mathematical, and Spatial IQ.

2. The ROADS assessment battery (Kornilov \& Grigorenko, 2010) measures analytical, practical and creative abilities as defined in Sternberg's (1999) theory of successful intelligence. It consists of 6 subtests: 2 CFIT Scale 2 subtests (Cattell \& Cattell, 1973), 2 verbal intelligence subtests, practical intelligence (situational judgement) subtest, and the Creative Stories subtests. We retained the Fluid IQ and creativity scores for the purposes of the study. The measure of creativity was computed through item-response theory modeling (Bond \& Fox, 2001; Linacre, 2009) using the ratings of Originality, Complexity, Emotionality and Task Appropriateness of the creative stories that participants were asked to write given one of the five pre-defined topics. Three independent raters provided their ratings $(K=.85,89.7 \%$ agreement, person reliability $=.85$ ).

3. Cartoon Task (Sternberg \& Rainbow Project Collaborators, 2006) measures creativity based on experts' ratings of Originality, Complexity, Humor and Task Appropriateness of the captions generated by participants in response to the cartoons adapted from NY Times (32.6\% agreement, person reliability .65). 


\section{Results}

\section{Correlational analysis}

Tables 1 and 2 show the matrices of intercorrelations for studies 1 and 2, respectively. In study 1 , Cartoon Task creativity was positively related to tolerance for uncertainty as measured by NQTU (TU; $r=.20$, $p<.05)$, and General and Spatial IQ $(r=.19, p<.05)$. This suggests that both general intelligence and a personality trait of tolerance for uncertainty are related to the productivity of creative activity (note that Spatial IQ includes some elements of imagination, i.e., mental rotation).

Study 2 showed a similar pattern of intercorrelations. Creativity as measured by Creative Stories significantly and positively correlated with Fluid IQ $(r=.15, p<.05)$ and negatively with intolerance for uncertainty as measured by TN-23 $(r=-.19, p<.05)$.

Table 1

Study 1 intercorrelations matrix

\begin{tabular}{l|cccccccc}
\hline & 1. & 2. & 3. & 4. & 5. & 6. & 7. & 8. \\
\hline 1. TU & & & & & & & & \\
2. ITU & .07 & & & & & & & \\
3. IPITU & $-.13^{* *}$ & -.06 & & & & & & \\
4. General IQ & .05 & $-.16^{*}$ & .04 & & & & & \\
5. Verbal IQ & .14 & $-.21^{* *}$ & .06 & $.82^{* *}$ & & & & \\
6. Mathematical IQ & .01 & -.11 & -.01 & $.84^{* *}$ & $.50^{* *}$ & & & \\
7. Spatial IQ & -.07 & -.01 & .05 & $.67^{* *}$ & $.29^{* *}$ & $.45^{* *}$ & & \\
8. Creativity CT & $.20^{\star}$ & .03 & -.04 & $.19^{*}$ & .14 & .12 & $.19^{*}$ & \\
\hline
\end{tabular}

Note: ${ }^{\star} \mathrm{p}<.05,{ }^{* *} \mathrm{p}<.01$. TU - tolerance for uncertainty, ITU - intolerance for uncertainty, IPITU - interpersonal intolerance for uncertainty, CT - Cartoon Task.

Study 2 intercorrelations matrix

Table 2

\begin{tabular}{l|cccc}
\hline & 1. & 2. & 3. & 4. \\
\hline 1. Riskiness & & & & \\
2. ITU & -.10 & & & \\
3. Fluid IQ & -.03 & $-.17^{\star}$ & & \\
4. Creativity CS & .03 & $-.19^{\star}$ & $.15^{\star}$ & \\
\hline
\end{tabular}

Note: ${ }^{\star} \mathrm{p}<.05$. ITU - intolerance for uncertainty, CS - Creative Stories. 
Intelligence and Tolerance / Intolerance for Uncertainty as Predictors of Creativity 251

In both cases the magnitude of the correlation coefficients for creativity and intelligence were comparable to those for creativity and tolerance / intolerance for uncertainty.

\section{Hierarchical regression analysis}

To test the hypothesis that tolerance / intolerance for uncertainty and intelligence have unique incremental predictive power in predicting creativity, two hierarchical regression analyses were performed. In both cases creativity was a dependent variable, intelligence was entered into a model at the first step, and tolerance / intolerance for uncertainty was entered at the second step. We used pairwise intercorrelations matrices to account for missing data.

Table 3 presents the results of two regression analyses. In both cases, tolerance / intolerance for uncertainty had unique predictive power over intelligence when predicting creativity. In study 1 , tolerance for uncertainty positively predicted creativity $(\beta=.19, p<.05)$, explaining additional $3.5 \%$ of the variance $\left(\Delta \mathrm{R}^{2}=.035, p<.05\right)$ in creativity as measured by Cartoon Task above and beyond the variance explained by General IQ $(\beta=.18, p<.05)$. In study 2 , intolerance for uncertainty negatively predicted $(\beta=-.17, p<.05)$ creativity, explaining additional $3.8 \%$ of the variance $\left(\Delta \mathrm{R}^{2}=.038, p<.05\right)$ in creativity as measured by Creative Stories above those explained Fluid IQ $(\beta=.12, p>.05)$, that lost its statistical significance after the intolerance for uncertainty was entered into the model.

Table 3

Hierarchical regressions

\begin{tabular}{|c|c|c|c|c|c|c|c|}
\hline \multicolumn{4}{|c|}{ Study 1 (DV - Cartoon Task creativity) } & \multicolumn{4}{|c|}{ Study 2 (DV - Creative Stories creativity) } \\
\hline \multirow{3}{*}{$\begin{array}{l}\text { Model } 1 \\
\text { General IQ }\end{array}$} & $\beta$ & $\mathrm{t}$ & Parameters & \multirow{3}{*}{$\begin{array}{l}\text { Model } 1 \\
\text { Fluid IQ }\end{array}$} & $\beta$ & $\mathrm{t}$ & Parameters \\
\hline & & & $\mathrm{R}^{2}=.028$ & & \multirow[b]{2}{*}{$.15^{\star}$} & \multirow[b]{2}{*}{2.01} & $\mathrm{R}^{2}=.017$ \\
\hline & $.19^{*}$ & 2.10 & $\begin{array}{c}\mathrm{F}(1,118)=4.41 \\
\mathrm{p}<.05\end{array}$ & & & & $\begin{array}{c}\mathrm{F}(1,172)=4.05 \\
\mathrm{p}<.05\end{array}$ \\
\hline Model 2 & & & $\mathrm{R}^{2}=.055$ & Model 2 & & & $\mathrm{R}^{2}=.038$ \\
\hline General IQ & $.18^{*}$ & 2.03 & $\begin{array}{c}\mathrm{F}(2,117)=4.47 \\
\mathrm{p}<.05\end{array}$ & Fluid IQ & .12 & 1.64 & $\begin{array}{c}\mathrm{F}(2,171)=4.44 \\
\mathrm{p}<.05\end{array}$ \\
\hline TU & $.19^{*}$ & 2.10 & $\begin{array}{c}\Delta \mathrm{R}^{2}=.035 \\
\mathrm{p}<.05\end{array}$ & ITU & $-.17^{\star}$ & -2.18 & $\begin{array}{c}\Delta \mathrm{R}^{2}=.026 \\
\mathrm{p}<.05\end{array}$ \\
\hline
\end{tabular}

Note: ${ }^{\star} p<.05$. TU - tolerance for uncertainty (NQTU), ITU - intolerance for uncertainty (TN-23). 


\section{Discussion}

Both a positive relationship between tolerance for uncertainty and creativity, and a negative relationship between intolerance for uncertainty and creativity were established in the two studies that used different measures of creativity, intelligence and tolerance / intolerance for uncertainty. The correlational pattern depended on measures, with one study revealing a positive relationship between creativity and tolerance for uncertainty as measured by the NQTU questionnaire, and, the second study demonstrating a negative relationship between intolerance for uncertainty as measured by the TN-23 questionnaire. Together, these results suggest the need for further research that would use different measures of tolerance and intolerance for uncertainty simultaneously given the seeming dissimilarities between these two traits and processes mediating the actual genesis of the creative product.

The results also tentatively support the hypothesis about the relationship between creativity and two latent variables (acceptance of uncertainty and rejection of uncertainty) mentioned earlier (Kornilova, 2009). We suggest that these latent variables reflect the regulation of new formations by different personality traits (e.g., intuition, riskiness, selfestimated ability may also play the part) and the multidimensionality of sometimes counterintuitive processes that are involved in the actual genesis of the thinking strategies. However, the results obtained in the described studies allow us to accept the hypothesis about the positive relationship between tolerance for uncertainty and creativity and the negative relationship between intolerance for uncertainty and creativity, which joins the growing body of recent research on tolerance for uncertainty and creativity showing similar results (Wolfradt \& Pretz, 2001; Zenasni, Besancon, \& Lubart, 2009). Indirect support for the hypotheses tested in the studies also comes from the negative correlations between intelligence and intolerance for uncertainty observed in both studies suggesting that processes that underlie the rejection of uncertainty impede the generation of a creative product.

The results obtained through the use of two different measures of creativity in these studies speak in favor of their convergent validity and suggest that verbal creativity is characterized by the multiple processes involved in its regulation, thus, in the regulation of the activity that leads to new formations. Creativity as measured by the Cartoon Task requires 
Intelligence and Tolerance / Intolerance for Uncertainty as Predictors of Creativity 253

both tolerance for uncertainty and intelligence, whereas creativity as measured by the Creative Stories reveals not the possible supportive influence of tolerance for uncertainty, but impeding effects of intolerance for uncertainty. This again suggests that we need to view tolerance and intolerance for uncertainty as distinct traits and not the points on one continuum of tolerance / intolerance.

The hierarchical regression analyses revealed similar patterns of predictors of creativity, with tolerance for uncertainty having unique predictive power in creativity in study 1 and intolerance for uncertainty having unique predictive power in study 2 . The magnitudes of the effect sizes (both standardized regression coefficients and adjusted $\mathrm{R}^{2}$ ) speak in favor of a comparable effects of intellectual and personality components in the regulation of creative thinking. Creative decisions thus may be regulated by intellectual and personality components, and also by their interaction with the acts of accepting / rejecting uncertainty revealed in new formations - a hypothesis yet to be tested in further studies. Such interactions between intellectual and personality components may not be structurally defined and may depend on the actualization of the latent variables of accepting / rejecting uncertainty in the process of creation.

\section{Conclusions}

1. Tolerance for uncertainty positively predicts creativity, whereas intolerance for uncertainty demonstrates the opposite relationship with new formations revealed in creative products.

2. The value of general cognitive ability and intelligence in a person's "reservoir" in predicting creativity is comparable with that of personality traits of tolerance / intolerance for uncertainty.

3. The use of multiple measures of ability and personality traits in predicting creativity is important because it potentially allows us to both generalize the obtained relationships and restrict them to specific types of measures.

\section{References}

Amthauer, R. (1973). I-S-T 70. Intelligenz-Struktur-Test. Handanweisung. Göttingen: Hogrefe. 
Averill, J.R. (2000). Intelligence, Emotion and Creativity: From Trichotomy to Triunity. In R. Bar-On \& D.A. Parker (Eds.), Handbook of Emotional Intelligence (pp. 277-298). San Francisco: Jossey-Bass.

Babaeva, Yu.D., Berezanskaya, N.B., Vasiliev, I.A., Voiskounsky, A.E., \& Kornilova, T.V. (2008). Smyslovaâ teoriâ myšleniâ [The Sense Theory of Thinking]. Vestnik Moskovskogo universiteta. Seriâ 14 "Psihologiâ," 2, 26-58.

Baer, J., \& Kaufman, J.C. (2005). Bridging Generality and Specificity: The Amusement Park Theoretical (APT) Model of Creativity. Roeper Review, 27, 158-163.

Ball, G.A. (2009). Psihologičeskie principy sovremennogo gumanizma [The Psychological Principles of the Modern Humanism]. Voprosy psihologii, 6, 3-12.

Batey, M., \& Furnham, A. (2006). Creativity, Intelligence and Personality: A Critical Review of the Scattered Literature. Genetic, Social, and General Psychology Monographs, 132 (4), 355-429.

Bond T., \& Fox, C. (2001). Applying the Rasch model. Mahwah, NJ: Lawrence Erlbaum Associates.

Cattell, R.B., \& Cattell, H.E.P. (1973). Measuring Intelligence with the Culture Fair Tests. Champaign, IL: Institute for Personality and Ability Testing.

Collins, M.A., \& Amabile, T.M. (1999). Motivation and Creativity. In R.J. Sternberg (Ed.), Handbook of Creativity (pp. 297-312). Cambridge: Cambridge University press.

Dorner, D. (1997). The Logic of Failure: Recognizing and Avoiding Error in Complex Situations. Cambridge, MA: Perseus Press.

Frenkel-Brunswick, E. (1948). Tolerance Towards Ambiguity as a Personality Variable. American Psychologist, 3, 268-269.

Frenkel-Brunswick, E. (1949). Intolerance of Ambiguity as an Emotional and Perceptual Personality Variable. Journal of Personality, 18 (1), 108-136.

Furnham, A., \& Bachtiar, V. (2008). Intelligence and Personality as Predictors of Creativity. Personality and Individual Differences, 45, 613-617.

Guilford, J.P. (1962). Potentiality for Creativity. Gifted Child Quarterly, 6, 87-90.

Gottfredson, L.S. (1998). The General Intelligence Factor. Scientific American Presents, 9, 24-29.

Gurova, L.L. (1976). Psihologičeskij analiz rešeniâ zadač [The Psychological Analysis of Problem Solving]. Voronezh: Izdatel'stvo Voronežskogo universiteta.

Hunsaker, S.L., \& Callahan, C.M. (1995). Creativity and Giftedness: Published Instrument Uses and Abuses. Gifted Child Quarterly, 39, 110-114.

Hunt, M. (1997). How Science Takes Stock: The Story of Meta-Analysis. New York, NY: Russell Sage.

Kahneman, D., Slovic, P., \& Tversky, A. (Eds). (1982). Judgment Under Uncertainty: Heuristic and Biases. Cambridge: Cambridge University Press. 
Intelligence and Tolerance / Intolerance for Uncertainty as Predictors of Creativity 255

Kaufman, A.B., Kornilov, S.A., Bristol, A.S., Tan, M., \& Grigorenko, E.L. (In press). The Neurobiological Foundations of Creative Cognition. In: J.C. Kaufman \& R.J. Sternberg (Eds.), Cambridge Handbook of Creativity. Cambridge: Cambridge University Press.

Kerr, B., \& Gagliardi, C. (2003) Measuring Creativity in Research and Practice. In S.J. Lopez \& C.R. Snyder (Eds.), Positive Psychological Assessment: A Handbook of Models and Measures (pp. 155-169). Washington, DC: APA.

Kitaev-Smyk, L.A. (2007). Faktory naprâžěnnosti tvorčeskogo processa [The Tension Factors of Creative Process]. Voprosy psihologii, 3, 69-82.

Kornilov, S.A., \& Grigorenko, E.L. (2010). Metodičeskij kompleks dlâ diagnostiki analitičeskih, tvorčeskih i praktičeskih sposobnostej [The Assessment Battery for Analytical, Creative and Practical Abilities]. Psihologičeskij žurnal, 31 (2), 90-103.

Kornilov, S.A., Grigorenko, E.L., \& Smirnov, S.D. (2009). Longitûdnoe issledovanie akademičeskih, tvorčeskih i praktičeskih sposobnostej kak predposylok uspešnosti obučeniâ [A Longitudinal Study of Analytical, Creative and Practical Abilities as Predictors of Academic Achievement]. Voprosy psihologii, 5, 138-149.

Kornilova, T.V. (2003). Psihologiâ riska i prinâtiâ rerbenij [The Psychology of Risk and Decision Making]. Moscow: Aspekt Press.

Kornilova, T.V. (2009). Novyj oprosnik tolerantnosti k neopredelennosti [The New Questionnaire of Tolerance for Uncertainty]. Psihologičeskij žurnal, 30 (6), 140-152.

Kornilova, T.V., \& Tikhomirov, O.K. (1990). Prinâtie intellektual'nyh rešenij $v$ dialoge s komp'ûterom [Intellectual Decision Making in a Dialogue with a Computer]. Moscow: MGU.

Ladouceur, R., Talbot, F., \& Dugas, M.J. (1997). Behavioral Expression of Intolerance of Uncertainty in Worry. Behavior Modification, 21, 355-371.

Linacre, J.M. (2009). Facets Rasch Measurement computer program (version 3.65.0). Chicago.

Ma, H. (2009). The Effect Size of Variables Associated with Creativity: A MetaAnalysis. Creativity Research Journal, 21 (1), 30-42.

May, R. (1976). The Courage to Create. NY: Norman.

McKenzie, C.R.M. (1998). Taking into Account the Strength of an Alternative Hypothesis. Journal of Experimental Psychology: Learning, Memory, and Cognition, 24 (3), 771-792.

Mednick, S.A. (1962). The Associative Basis of the Creative Process. Psychological Review, 3, 220-232.

Nakamura, J., \& Csikszentmihalyi, M. (2003). The Motivational Sources of Creativity as Viewed from a Paradigm of Positive Psychology. In L.G. Aspinwall \& U.M. Staudinger (Eds.), A Psychology of Human Strengths: Fundamental Questions and Future Directions for a Positive Psychology (pp. 257-269). Washington, DC: APA. 
Plucker, J.A., \& Renzulli, J.S. (1999). Psychometric Approaches to the Study of Human Creativity. In R.J. Sternberg (Ed.), Handbook of Creativity (pp. 35-61). NY: Cambridge University Press.

Rhodes, M. (1961/1987). An Analysis of Creativity. In S.G. Isaksen (Ed.), Frontiers of Creativity Research: Beyond the Basics (pp. 216-222). Buffalo, NY: Bearly.

Runco, M.A. (2004). Creativity. Annual Review of Psychology, 55, 657-687.

Shalaev, N.V. (2007). Tolerantnost' k neopredelennosti v psihologičeskih teoriâh [The Tolerance for Uncertainty in Psychological Theories]. In A.K. Bolotov (Ed.), Celovek v situacii neopredelennosti (pp. 9-33). Moscow: TEIS.

Soldatova, G.U., \& Shaigerova, K. (Eds). (2008). Psihodiagnostika tolerantnosti ličnosti [The Psychodiagnostics of Tolerance of a Person]. Moscow: Smysl.

Sternberg, R.J. (1999). The Theory of Successful Intelligence. Review of General Psychology, 3 (4), 292-316.

Sternberg, R.J. (2006). Wisdom, Intelligence and Creativity Synthesized. NY: Cambridge University Press.

Sternberg, R.J., \& Lubart, T.I. (1996). Investing in Creativity. American Psychologist, 51, 677-688.

Sternberg, R.J., \& The Rainbow Project Collaborators. (2006). The Rainbow Project: Enhancing the SAT through Assessments of Analytical, Practical and Creative Skills. Intelligence, 34 (4), 321-350.

Tengano, D.W. (1990). Relationship of Tolerance of Ambiguity and Playfulness to Creativity. Psychological Reports, 66, 1047-1056.

Tikhomirov, O.K. (1969). Struktura myslitel'noj deâtel'nosti čeloveka [The Structure of the Thinking Activity of a Man]. Moscow: MGU.

Torrance, E.P. (1962). Guiding Creative Talent. Engelwood Cliffs, NJ: Prentice Hall.

Torrance, E.P. (1972). Predictive Validity of the Torrance Tests of Creative Thinking. Journal of Creative Behavior, 5, 236-252.

Vygotsky, L.S. (1934/1962). Thought and Language. Cambridge, MA: MIT Press.

Weisberg, R.W. (1999). Creativity and Knowledge: A Challenge to Theories. In R.J. Sternberg (Ed.), Handbook of Creativity (pp. 226-250). NY: Cambridge University Press.

Wolfradt, U., \& Pretz, J.E. (2001) Individual Differences in Creativity: Personality, Story Writing, and Hobbies. European Journal of Personality, 15, 297-310.

Zenasni, F., Besancon, M., \& Lubart. T. (2008). Creativity and Tolerance of Ambiguity: An Empirical Study. Journal of Creative Behavior, 42 (1), 61-73.

Zinchenko, V.P.(2007). Tolerantnost'k neopredelennosti: novost' ilipsihologičeskaâ tradiciâ? [Tolerance for Uncertainty: News or a Psychological Tradition?]. In A.K. Bolotov (Ed.), Čelovek v situacii neopredelennosti (pp. 254-278). Moscow: TEIS. 